\title{
Caracterização experimental da relação momento-rotação de ligação viga-pilar em concreto pré-moldado
}

\section{Experimental characterization of the moment- rotation relationship of the beam-column connection in precast concrete}

Maria Angela Simões Hadade ${ }^{1}$, Bruna Catoia ${ }^{1}$, Marcelo de Araujo Ferreira ${ }^{1}$, Roberto Chust Carvalho ${ }^{1}$

\footnotetext{
${ }^{1}$ Núcleo de Estudo e Tecnologia em Pré-moldados de Concreto (NETPre). Departamento de Engenharia Civil da Universidade Federal de São Carlos - Deciv/UFSCar, Rod. Washington Luis, km 235 - São Carlos, São Paulo, Brasil. e-mail: angelahadade@gmail.com, bcatoia@ufscar.br, marceloaferreira@uol.com.br, robertochustcarvalho@gmail.com
}

\section{RESUMO}

No presente artigo, apresenta-se o resultado de uma investigação experimental sobre o comportamento semirrígido de ligações típicas viga-pilar em estruturas pré-moldadas de concreto armado, projetadas para resistir ao momento fletor negativo por meio de armadura de continuidade solidarizada no local passante em bainhas corrugadas com preenchimento de graute em pilar central. O programa experimental envolveu 6 ensaios de protótipos cruciforme de ligações viga-pilar em escala real, onde o detalhamento da armadura negativa foi mantido igual para todos os modelos, mas variou-se o detalhamento das ligações positivas $\mathrm{n}$ o apoio da viga sobre o consolo, sendo 2 modelos com almofadas de elastômero e chumbadores verticais, 2 modelos com junta grauteada e chumbadores verticais e 2 modelos com chapas soldadas positivas. Com base nos resultados experimentais, observou-se que o detalhamento na ligação positiva apresentou influência secundária sobre a rigidez secante negativa da ligação viga-pilar, onde a rigidez média obtida nos modelos com chapas soldadas foi cerca de $11 \%$ superior à rigidez média obtida nos modelos com almofadas de elastômero. Portanto, pode-se concluir que a rigidez secante negativa é fortemente associada com o mecanismo de deformação por alongamento da armadura negativa, com escorregamento aço-concreto nas posições fissuradas da região da ligação anterior ao escoamento da armadura, com intensificação deste mecanismo com a abertura na interface viga-pilar a partir do arrancamento parcial de graute de preenchimento na bainha corrugada. Considerando uma viga de concreto armado com rigidez secante $\left(E_{c} I\right)_{s e c}=0,5 E_{c} I$ e comprimento virtual $L=$ $12 h(h=$ altura da viga), obteve-se um coeficiente médio de engastamento parcial em torno de $65 \%$.

Palavras-chave: Estruturas pré-moldadas, ligações viga-pilar, rigidez, metodologia experimental.

\section{ABSTRACT}

This paper presents the results of an experimental investigation on the semi-rigid behaviour of typical beamcolumn connections for precast concrete structures, designed to resist negative bending moment with continuity bars crossing the central column through corrugated sleeves filled with grout with cast-in-place topping on the precast beams. The experimental program involved 06 tests with cruciform prototypes with large scale of beam-column connections, where the detail of the negative continuity bars was the same for all the models, varying the positive connections of the beam support on the corbel, being 2 models with bearing pads with elastomer and dowel bars, 2 models with grouted joint and dowel bars and 2 models with positive welded plates. Based on the experimental results, it was observed that the positive connections had a secondary influence on the negative secant stiffness of the beam-column connections, wherein the average stiffness achieved for the models with welded plates was just $11 \%$ higher than the stiffness obtained for the models with elastomeric pads. On the other hand, it can be deduced that the secant stiffness is strongly associated with the elongation deformation mechanism of the negative reinforcement, with bond-slip at the cracked positions of the connection region prior the yielding of the rebars, with the increasing of the opening of the beam-column interface due to partial pullout of the grout from the corrugated sleeve. Considering a rein- 
forced concrete beam with secant stiffness of $\left(E_{c} I\right)_{\text {sec }}=0,5 E_{c} I$ and a virtual length $L=12 h$ ( $h=$ beam height), it has been obtained a partial restrainement of $65 \%$.

Keywords: Precast structures, beam-column connections, stiffness, experimental methodology.

\section{INTRODUÇ̃̃O}

O grau de mobilização de momentos fletores nas ligações viga-pilar está relacionado com a capacidade de restrição às rotações nas extremidades das vigas pré-moldadas. Enquanto ligações rígidas apresentam uma restrição total das rotações e as ligações articuladas liberam totalmente as rotações, o grau de engastamento parcial ou da transferência parcial dos momentos fletores nas ligações semirrígidas depende da inter-relação da rigidez da viga pré-moldada conectada e da rigidez secante da relação momento-rotação da ligação vigapilar analisada. Quando a estabilidade lateral das construções pré-moldadas é provida por ação de pórtico, as ligações viga-pilar devem ser capazes de transmitir com eficiência os momentos fletores nas extremidades das vigas, atendendo aos requisitos de resistência, rigidez e ductilidade. O desempenho das ligações vigapilar afeta tanto o comportamento local das vigas adjacentes quanto o comportamento global da estrutura prémoldada.

Embora em situaç̃oes correntes de projeto as ligações com resistência à flexão sejam idealizadas como rígidas, ELLIOTT et al [1] demonstraram que as ligações típicas viga-pilar com armadura de continuidade com concretagem no canteiro apresentam comportamento semirrígido, havendo uma rotação associada ao momento resistido pela ligação. Em geral, o comportamento semirrígido das ligações viga-pilar pré-moldadas ocorre após a formação da fissuração e anterior ao escoamento da armadura, principalmente quando os mecanismos de deformação por alongamento da armadura de continuidade estão associados à escorregamentos da armadura com abertura da junta viga-pilar em função do arrancamento parcial do graute nas bainhas preenchidas nos pilares centrais ou de escorregamento aço-concreto nas regiões fissuradas na região da ligação entre a interface viga-pilar e a posição do centro de rotação sobre o apoio no consolo.

A aplicação de pórticos pré-moldados com ligações viga-pilar resistentes à flexão com pilares contínuos se tornou uma prática corrente no Brasil desde os anos 1980. No caso das ligações viga-pilar rígidas, como no caso das ligações com chapas soldadas negativas e positivas, tem-se a dificuldade para absorver as deformações decorrentes das mudanças de volume, ocasionando forças não intencionais nas ligações e na estrutura. Portanto, é preferível adotar o conceito do engastamento parcial, onde o momento resistido é alcançado para uma rotação limitada.

Em função do grau de restrição à rotação, haverá um engastamento parcial associado, o qual depende da relação entre a rigidez da ligação e a rigidez da viga pré-moldada, após sua solidarização. O fator que relaciona estes dois parâmetros é denominado de fator de restrição (ou fator de rigidez). O comportamento semirrígido nas extremidades das vigas faz com que haja uma transmissão parcial dos momentos fletores nas ligações, com o aumento de momentos positivos nos vãos devidos às ações gravitacionais. Além disso, as ligações semirrígidas aumentam os deslocamentos laterais globais de primeira ordem na estrutura prémoldada, afetando a redistribuição de momentos entre vigas e pilares, mas principalmente aumentando os efeitos globais de segunda ordem.

Segundo a ABNT NBR9062 [2], o comportamento semirrígido de uma ligação viga-pilar é caracterizado pela sua rigidez secante $\left(R_{s e c}\right)$, a qual representa a resposta não linear da relação momento-rotação, conforme indicada na Figura 1. A rotação relativa viga-pilar, a qual é associada à rigidez secante, deve ser medida no centro de giro no apoio sobre o consolo, conforme Figura 2. $\mathrm{O}$ fator de restrição à rotação $\alpha_{R}$ relaciona a rigidez secante da ligação viga-pilar com a rigidez da viga adjacente por ela conectado (Equação 1).

$$
\boldsymbol{\alpha}_{\boldsymbol{R}}=\left[1+\frac{3\left(\boldsymbol{E}_{\boldsymbol{c}} \boldsymbol{I}\right)_{\mathrm{sec}}}{\boldsymbol{R}_{\mathrm{sec}} \boldsymbol{L}_{e f}}\right]
$$

Onde:

$L_{e f}: \quad$ Comprimento efetivo entre os centros de giros nos apoios da viga, conforme Figura 3

$\left(E_{c} I\right)_{\text {sec }}$ : Rigidez secante da viga considerada na análise estrutural

Sendo:

$\left(E_{c} I\right)_{s e c}=0,5 E_{c} I \quad$ (Rigidez secante da viga pré-moldada em concreto armado, segundo ABNT NBR9062 [2])

$\left(E_{c} I\right)_{s e c}=0,8 E_{c} I \quad$ (Rigidez secante da viga pré-moldada em concreto protendido, segundo ABNT NBR9062

[2]) 
Para fins de caracterização da rigidez secante experimental obtida em ensaios cruciforme, onde se tem apenas um trecho da viga, FERREIRA [3] sugere que se considere um comprimento virtual $L=12 h$ ( $h$ a altura da viga) para o caso de viga pré-moldadas em concreto armado. Com base no fator de restrição $\alpha_{R}$, o coeficiente de engastamento parcial da ligação viga-pilar pode ser calculado pela Equação 2.

$$
\gamma_{E P}=\frac{3 \alpha_{R}}{2+\alpha_{R}}
$$

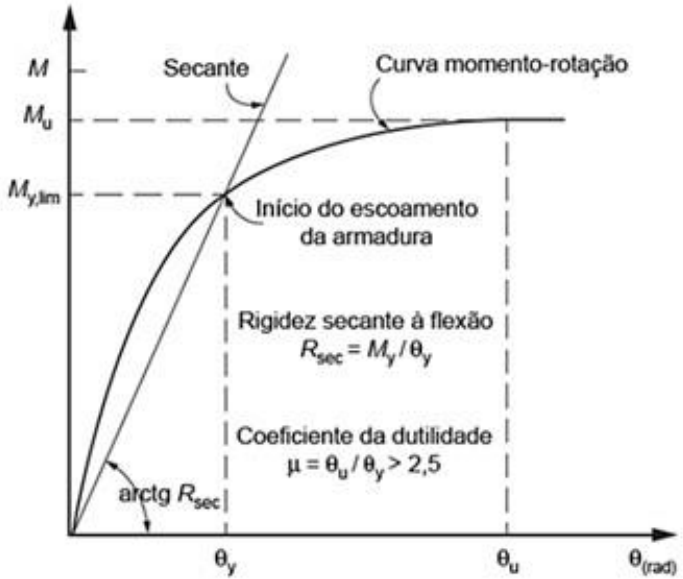

\section{Legenda}

$R_{\text {sec }}$ rigidez secante da curva momento-rotação da ligação viga-pilar

My,lim momento-limite no inicio do escoamento da armadura de continuidade da ligaçăo viga-pilar

Mu momento último na extremidade da viga no limite de plasticaçăo da ligaçăo viga-pilar

by rotaçăo relativa viga-pilar no inicio do escoamento da armadura de continuidade

Qu rotaçäo relativa viga-pilar máxima no limite de plasticaçăo da ligaçăo

$\mu \quad$ coeficiente de ductilidade da relação momento-rotação da ligação viga-pilar

Figura 1: Curva momento-rotação (Fonte: NBR9062 [2])

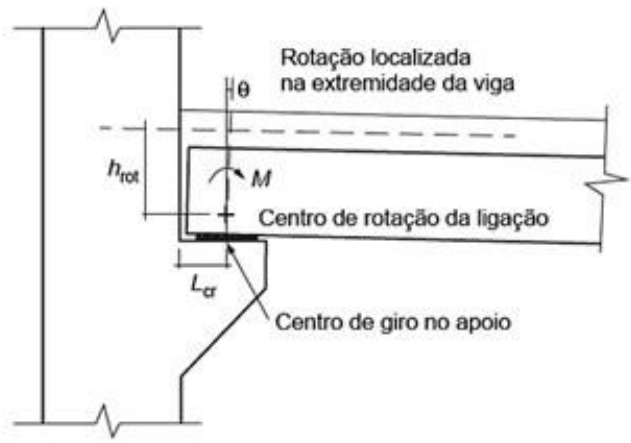

\footnotetext{
Legenda

$L_{c r} \quad$ distância da face do pilar até o centro de rotaçăo

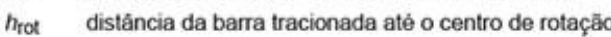

Figura 2: Centro de giro no apoio da viga pré-moldada (Fonte: NBR9062 [2]) 

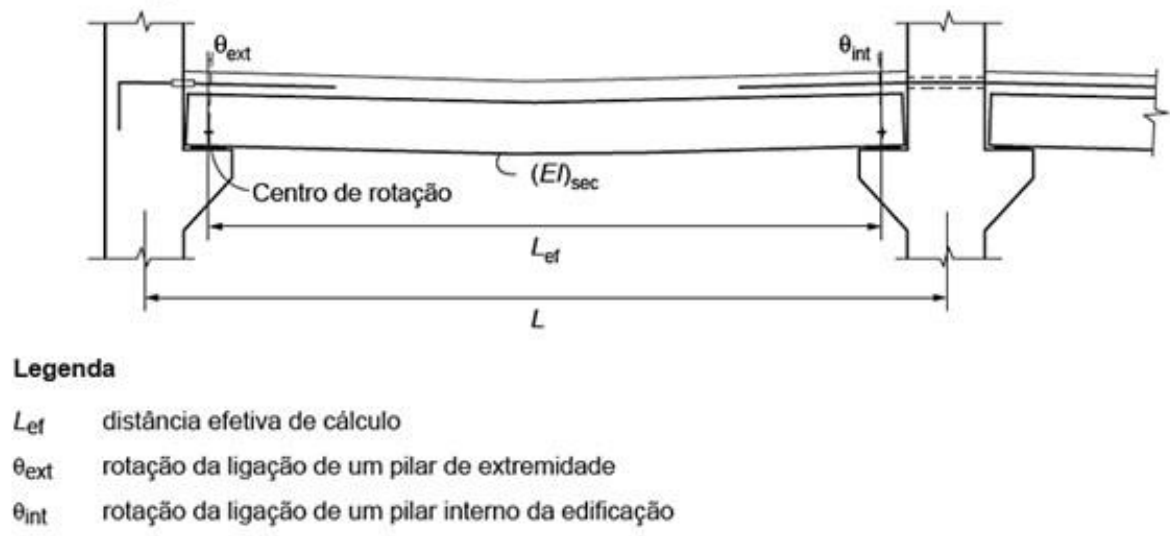

Figura 3: Comprimento efetivo da viga para cálculo do fator de restrição (Fonte: NBR9062 [2])

\section{MATERIAIS E MÉTODOS}

Este artigo apresenta os principais resultados experimentais da pesquisa desenvolvida em HADADE [4], cujo principal objetivo foi a caracterização experimental da rigidez secante à flexão negativa em ligações vigapilar com armadura de continuidade atravessando um pilar central por meio de bainha corrugada preenchida com graute. O programa experimental envolveu 6 ensaios de protótipos cruciforme de ligações viga-pilar em escala real, onde o detalhamento da armadura negativa foi mantido igual para todos os modelos, variando-se o detalhamento das ligações positivas no apoio da viga sobre o consolo, sendo 2 modelos com almofadas de elastômero e chumbadores verticais (Figura 4a), 2 modelos com junta grauteada e chumbadores verticais (Figura 4b) e 2 modelos com chapas soldadas positivas (Figura 4c).
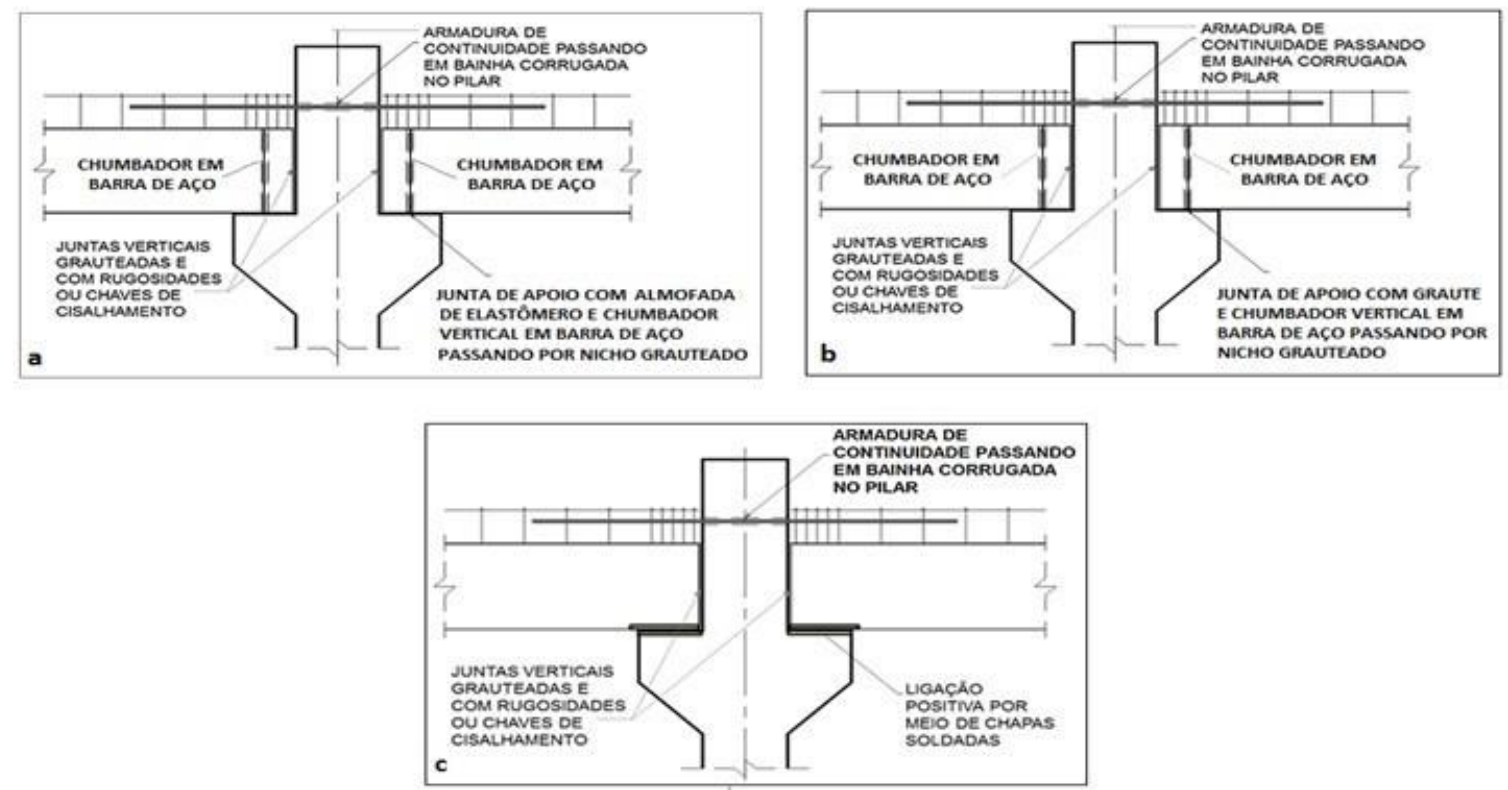

Figura 4: Detalhamento nas juntas de apoio com: a) almofada de elastômero b) graute e ambas com chumbador vertical. c) chapa soldada (Fonte: Adaptado de Projeto de Revisão da ABNT NBR 9062 [2])

Neste item são apresentados os modelos ensaiados e os ensaios experimentais realizados, assim como as metodologias empregadas. O programa experimental deste trabalho teve por objetivo a caracterização do comportamento de ligações viga-pilar largamente utilizadas no Brasil. Para reproduzir essas ligações foram projetados seis protótipos com disposição cruciforme, compostos por um pilar central munido de dois consolos em faces opostas, os quais apoiavam uma das extremidades da viga, também conectada ao pilar nessa região através das armaduras de continuidade, que atravessavam-no por meio de duas bainhas corrugadas preenchidas por graute. Estas ligações eram resistentes a momento negativo e as vigas tinham a outra extremidade em balanço na qual aplicaram-se cargas verticais com a utilização de atuadores. Os referidos modelos, 
todos com a mesma ligação negativa, foram distribuídos dois a dois por três séries. Cada série possuía uma tipologia diferenciada de junta de apoio, além de taxas de armadura transversal distintas na zona da ligação para cada um dos modelos. Para a primeira série, as vigas ligavam-se ao consolo por meio de chumbador vertical e apoiavam-se em almofada de neoprene (elastômero sintético de policloropreno). Para a segunda, a ligação foi por meio de chapas soldadas entre si e a terceira também utilizou chumbadores verticais e graute. Tal arranjo possibilitou a simulação da situação real de uma região próxima a um nó central de uma estrutura aporticada (Figura 5).

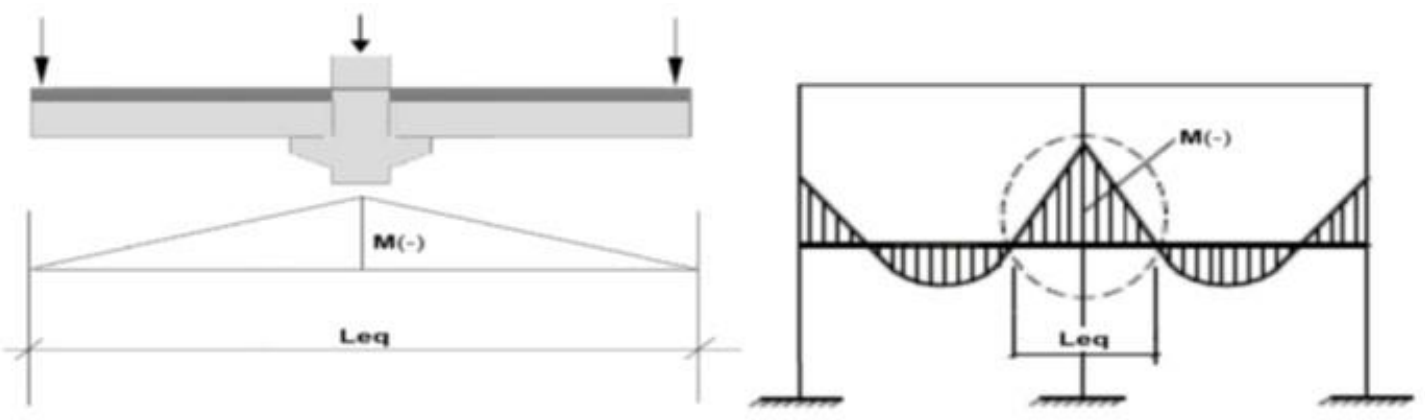

Figura 5: Simulação de estruturas aporticadas, FERREIRA [3]

\subsection{Confecção dos modelos}

Os protótipos foram realizados em concreto armado e dimensionados conforme a ABNT NBR 6118 [5] e ABNT NBR 9062 [2] para resistir a uma carga de $184 \mathrm{kN}$ aplicada na extremidade livre de cada viga. Os pilares possuíram seção transversal de $500 \mathrm{~mm}$ x $500 \mathrm{~mm}$ e altura de $210 \mathrm{~mm}$ e foram munidos de dois consolos com dimensões de $350 \mathrm{~mm}$ x $500 \mathrm{~mm}$ x $500 \mathrm{~mm}$, dois chumbadores em CA25 com $20 \mathrm{~mm}$ de diâmetro para cada consolo dos modelos NCE (neoprene, chumbador e estribo), NC (neoprene e chumbador), GC (graute e chumbador) e GCE (graute, chumbador e estribo) e chapa de $250 \mathrm{~mm}$ x $400 \mathrm{~mm}$ x 12,5 mm para os CS (chapa soldada) e CSE (chapa soldada e estribo). As pré-vigas apresentaram largura de $500 \mathrm{~mm}$, comprimento de $2500 \mathrm{~mm}$ e altura de $600 \mathrm{~mm}$. O seu complemento, moldado no local, destinado a solidarização da estrutura apresentou uma altura de $280 \mathrm{~mm}$ para os NCE, NC, GC e de $240 \mathrm{~mm}$ para CS, CSE e GCE. A sequência de montagem dos modelos ocorreu de acordo com a Figura 6, da seguinte maneira:

1) Posicionamento do equipamento de fixação inferior do pilar;

2) Posicionamento do pilar;

3) Travamento do pilar por meio de parafusos existentes no equipamento de fixação inferior;

4) Posicionamento do equipamento de fixação superior do pilar;

5) Travamento do pórtico de reação central;

6) Posicionamento do pilar no prumo;

7) Travamento do pilar de concreto no pórtico de reação central por meio de parafusos existentes no equipamento de travamento superior;

8) Posicionamento de apoios provisórios para a montagem das pré-vigas;

9) Posicionamento das pré-vigas;

10) Nivelamento das pré-vigas;

11) Posicionamento das armaduras negativas já devidamente instrumentadas, através de nichos com bainhas corrugadas existentes no pilar;

12) Preenchimento com graute dos nichos existentes nas pré-vigas por onde passaram os chumbadores localizados nos consolos para os modelos NCE, NC, GCE, GC ou colocação de parafusos mantenedores do posicionamento das pré-vigas dos modelos CSE, CS;

13) Colocação das fôrmas em madeira na região das juntas verticais pré-vigas-pilar e horizontais no caso dos modelos GC e GCE.

14) Preenchimento com graute dos nichos por onde passaram as barras de aço negativas;

15) Preenchimento com graute dos espaços entre as pré-vigas e o pilar (juntas verticais) e das horizontais, quando necessário;

16) Colocação de fôrmas em madeirite, com dimensões previstas em projeto, ao longo do perímetro 
das pré-vigas para a concretagem das partes complementares destas. Estas fôrmas foram apoiadas nas prévigas, fixadas por meio de arame e tarugos de aço e alguma possível brecha, vedada com papel grosso úmido;

17) Colocação de travas de madeira no topo para evitar a abertura das fôrmas;

18) Concretagem da complementação das pré-vigas;

19) Solda das chapas de aço existentes em regiões inferiores das pré-vigas e superiores dos consolos.
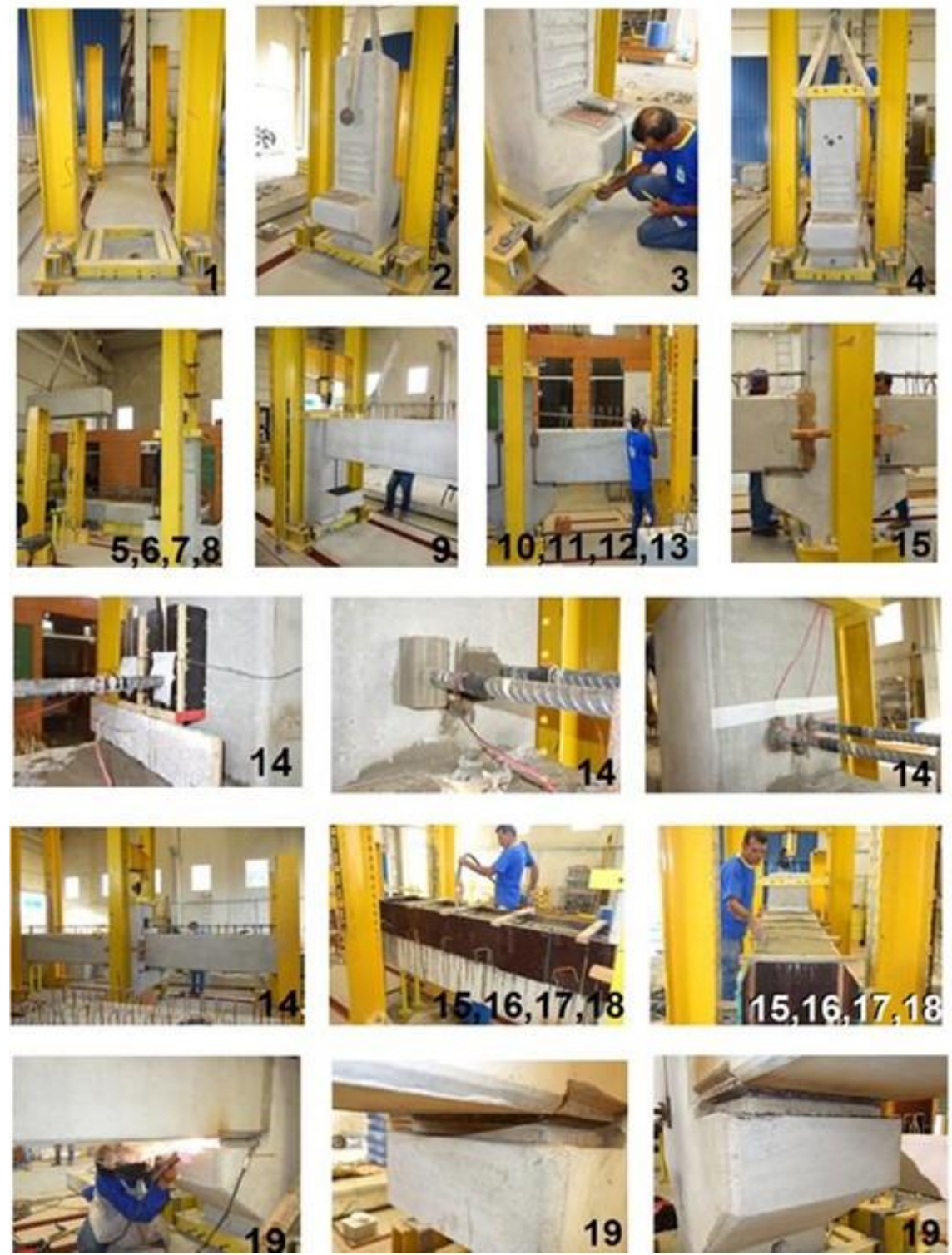

Figura 6: Sequência de montagem dos modelos.

\subsection{Ensaios experimentais}

$\mathrm{O}$ ensaio em cada modelo, compostos individualmente por duas vigas com ligações resistentes à flexão, em uma das extremidades e balanço na outra, suportadas por um pilar central com dois consolos em faces opostas, foi realizado com a utilização de 3 atuadores hidráulicos posicionados no centro do pilar e extremidades livres das vigas. Estes equipamentos apresentaram capacidade de $500 \mathrm{kN}$ e foram alimentados por uma bomba manual. A carga de escoamento de projeto foi estimada em $184 \mathrm{kN}$ para cada um dos dois pontos de aplicação, localizados no eixo central longitudinal das vigas. O tipo de carregamento foi incremental com aplicação monotônica. Durante a realização dos ensaios foram aplicados 3 carregamentos, atingindo cerca de $40 \%$ do carregamento último no primeiro e $100 \%$ do carregamento último no derradeiro. Realizou-se esse procedimento com o intuito de verificar o comportamento secante da rigidez à flexão nas ligações viga-pilar. A distância entre o ponto de aplicação da força e o centro de giro da ligação variou entre $211 \mathrm{~mm}$ a $218 \mathrm{~mm}$ conforme o modelo. Os modelos ensaiados podem ser observados na Figura 7. 

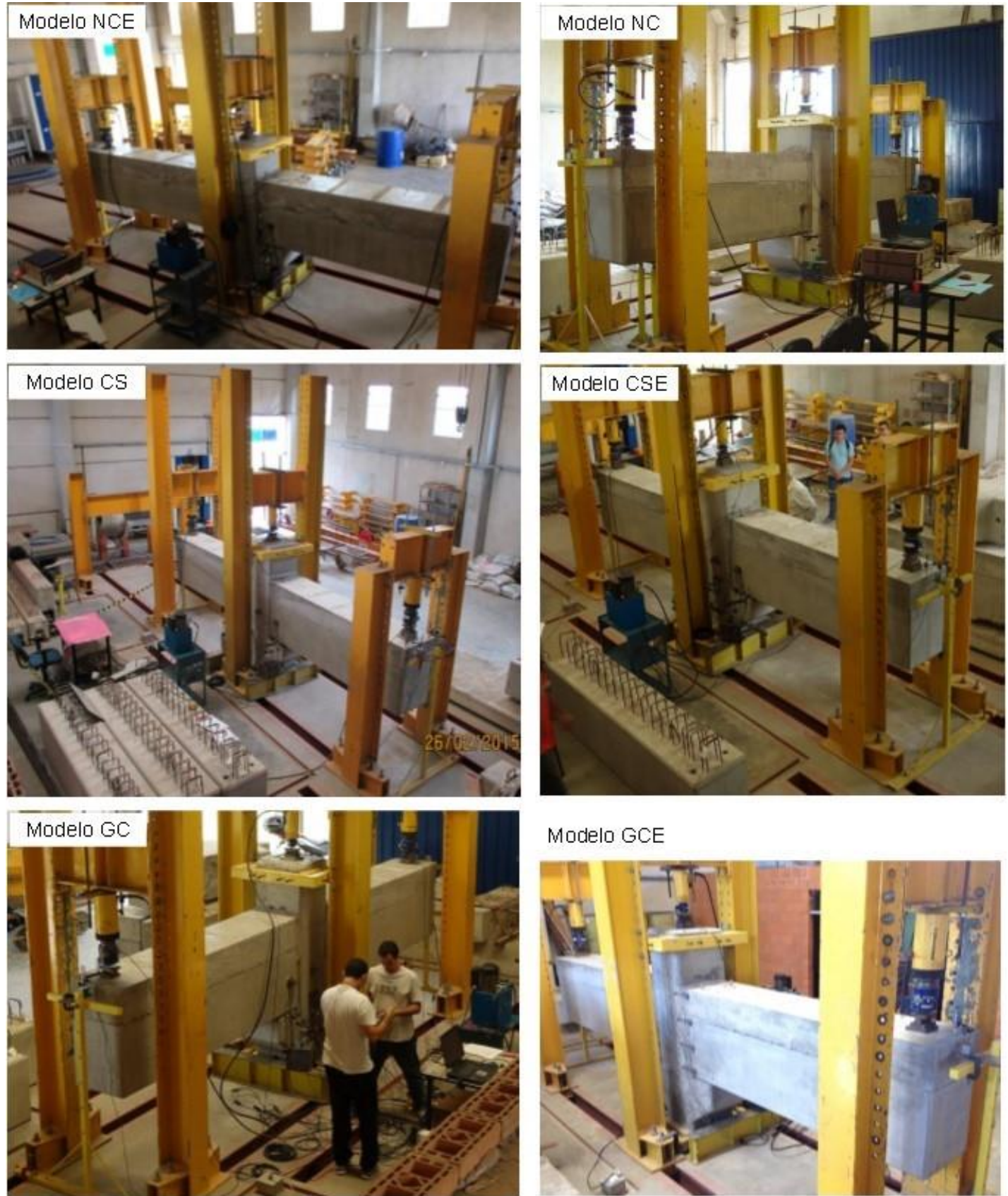

Figura 7: Modelos ensaiados.

Para a aferição de deslocamentos lineares e angulares em pontos estratégicos da estrutura, idealizou-se um esquema composto pelos seguintes instrumentos de medição: 3 células de carga que forneceram leituras de força; 3 atuadores hidráulicos, utilizados para a aplicação de cargas nos pilares e vigas, 8 transdutores LVTD (Linear Variable Differential Transducers) ; 4 extensômetros elétricos de resistência (Strain Gages); 2 ou 4 extensômetros elétricos com base removível, os quais forneceram leituras de deslocamento linear e 3 clinômetros que disponibilizaram leituras de rotação. O detalhe dos instrumentos empregados podem ser observados na Figura 8. 


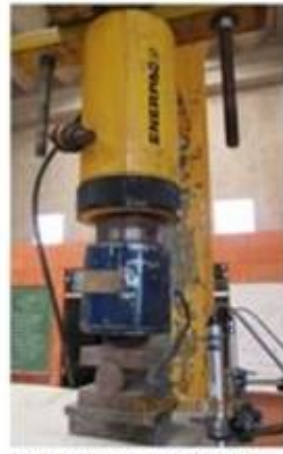

CILINDRO HIDRAUULICO CÉLULA DE CARGA

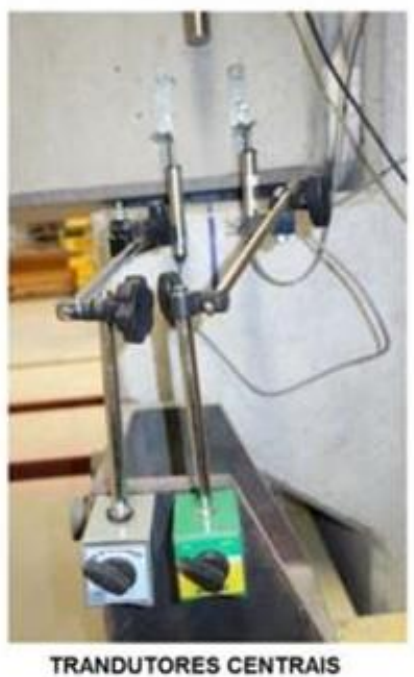

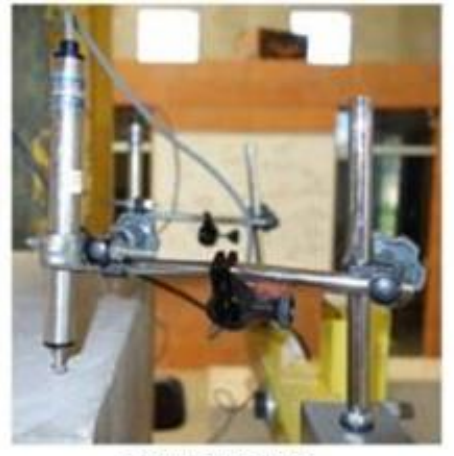

TRANSDUTORES
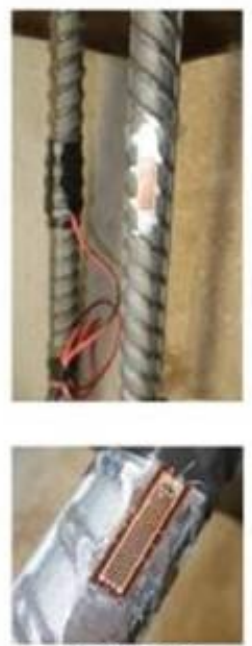

STRAIN GAGE

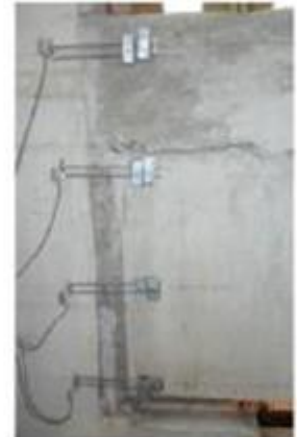

EXTENSÓMETROS DE BASE REMOVIVEL.

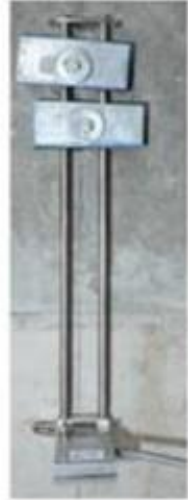

- EXTENSÓMETROS ELÉtRICOS DE RESISTÉNCIA (STRAIN GAGES)

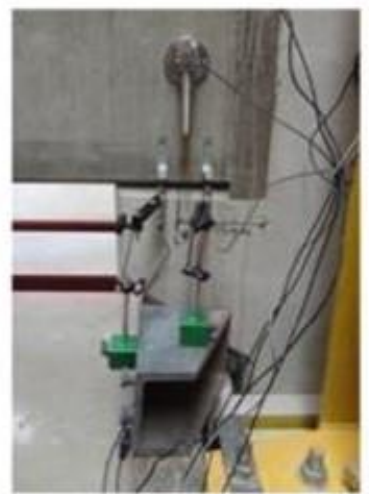

CLINOMETRO E TRANDUTORES

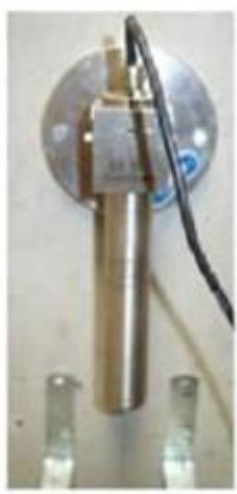

CLINOMMETRO

Figura 8: Detalhe dos instrumentos empregados nos ensaios.

O posicionamento de cada instrumento de medição foi escolhido estrategicamente para a obtenção dos dados necessários à análise dos modelos, assim:

Os atuadores hidráulicos com as células de carga foram localizados nas extremidades em balanço das vigas, por serem esses pontos os mais desfavoráveis à aplicação de cargas, uma vez que, por estarem mais distantes do apoio, geravam os maiores momentos fletores possíveis. Em cada extremidade livre, também foram colocados transdutores, para que fossem medidos os deslocamentos verticais máximos das vigas abaixo das cargas. Outros transdutores foram fixados nas imediações do centro de rotação da ligação com o intuito de permitir a obtenção dos deslocamentos verticais e indiretamente as rotações nesses pontos. Houve também a preocupação de que os transdutores não fossem posicionados em locais onde possivelmente ocorreriam fissuras, de modo a não inviabilizar suas leituras, desta forma optou-se pela colocação destes na região dos consolos. Os extensômetros elétricos de base removível foram distribuídos na região da junta vertical, cruzando-a próximos às fibras mais tracionadas e mais comprimidas da viga para todos os modelos e também na parte central desta, para três dos protótipos (CSE, GCE e GC), com a finalidade de aferir deslocamentos tanto lineares com angulares. Com as medidas obtidas a partir desses instrumentos, também pode-se determinar a posição da linha neutra da viga. Os três clinômetros foram fixados onde supostamente seriam os centros de rotação das ligações e no centro do pilar para que fossem determinadas as rotações das ligações e as rotações relativas entre vigas e pilar. Os clinômetros foram localizados na região inferior da viga, com o intuito de diminuir o risco de erros de leitura devido à possibilidade de fissuração no topo da mesma. Os straingauges das armaduras negativas foram colados no alinhamento próximo ao centro de rotação de cada junta para que fosse possível medir a deformação das barras de continuidade nesta zona.

Todos os equipamentos de medição foram conectados ao sistema de aquisição de dados (Sistem 5000), que forneceu as leituras diretamente ao computador conectado a ele. A instrumentação dos modelos pode ser observada na Figura 9. 


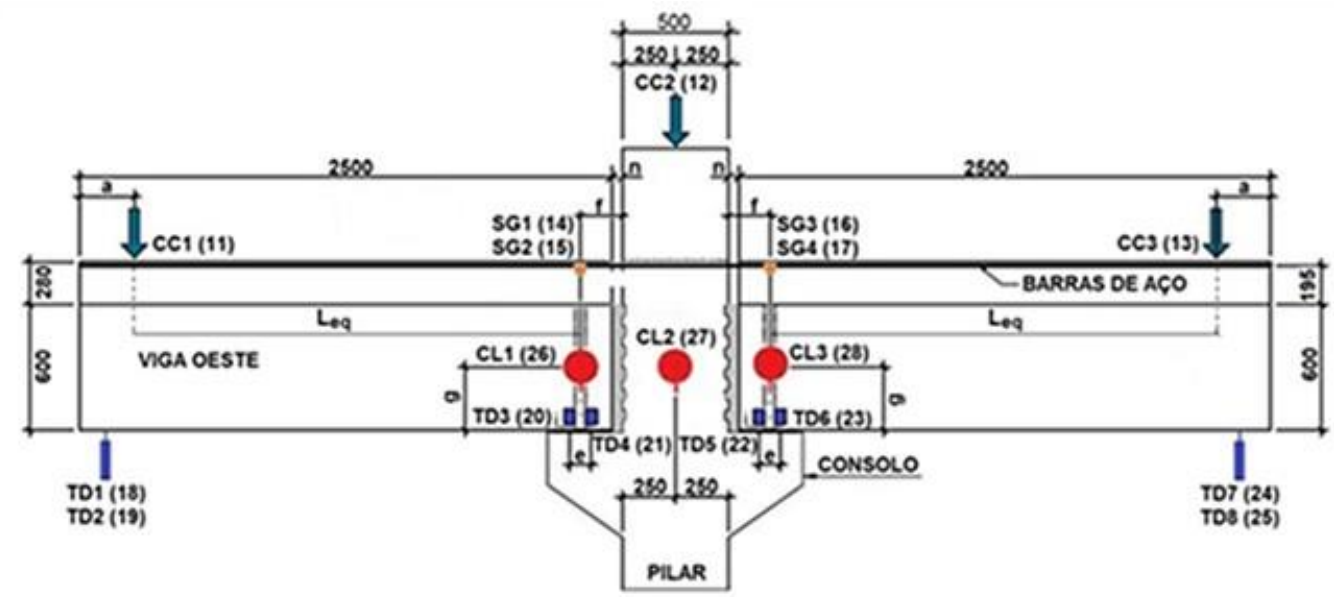

Figura 9: Modelo de instrumentação utilizada em todos os modelos ensaiados.

\subsection{Propriedades mecânicas dos materiais}

Os materiais empregados nos modelos e suas respectivas características são descritas a seguir:

\section{- Concreto}

A resistência dos concretos, tanto dos elementos pré-fabricados quanto do complemento das pré-vigas moldados no local, foram asseguradas por meio de dosagens e verificadas através de ensaios à compressão de corpos-de-prova cilíndricos com dimensões de $150 \mathrm{~mm}$ x $300 \mathrm{~mm}$, realizados de modo geral no dia do rompimento dos modelos. O concreto das pré-vigas atingiu $50 \mathrm{MPa}$ e o concreto moldado no local para complemento da pré-viga atingiu $30 \mathrm{MPa}$, aos 28 dias.

\section{- Graute}

O graute foi utilizado para preencher nichos que abrigaram as armaduras longitudinais de continuidade e do chumbador, além das interfaces viga-pilar e viga-consolo. Para isso foi utilizado um produto em pó pronto à base de cimento Portland, agregados naturais e aditivos que misturado à agua na proporção indicada, transformou-se em argamassa fluida, inerte em relação ao aço da armadura com características de alta resistência à compressão, de baixa permeabilidade à água, de auto nivelamento e retração controlada, propícia ao trabalho em áreas de difícil acesso como bainhas e juntas. Para o NCE foi atingido 62,46 MPa aos 26 dias, para o CS 50,7 MPa aos 48 dias e para o GC 55,26 MPa aos 12 dias.

- Aço

Para os elementos de concreto armado dessa pesquisa, foram utilizados aços CA25 e CA50 nas bitolas de 6 $\mathrm{mm}, 3 \mathrm{~mm} ; 8 \mathrm{~mm} ; 16 \mathrm{~mm}$ e $25 \mathrm{~mm}$.

- Solda

A solda executada na ligação das chapas de aço, com dimensões de $290 \mathrm{~mm}$ x $400 \mathrm{~mm}$ x 12,5 mm, existentes no topo dos consolos e parte inferior das pré-vigas dos modelos CSE e CS ocorreu ao longo das três faces do inserto com eletrodo 7018 OK 4804 na bitola de 3,5 mm regulada pela norma AWS:E7018 (American Welding Standard). As dimensões do filete de solda, perna (espessura) com $10 \mathrm{~mm}$ e garganta (altura) com $7 \mathrm{~mm}$ foram determinadas através da força normal solicitante gerada pelo momento fletor na seção onde houve a solda. Detalhe da solda pode ser observado na Figura 10.

- Almofada de apoio

A almofada de apoio para os modelos NCE e NC foram de elastômero sintético de policloropreno (neoprene), com dimensões de $400 \mathrm{~mm}$ x $250 \mathrm{~mm}$ x $15 \mathrm{~mm}$, dureza Shore igual a 60 e $\square_{\text {máx }}=10 \mathrm{MPa}$. (Figura 10). 


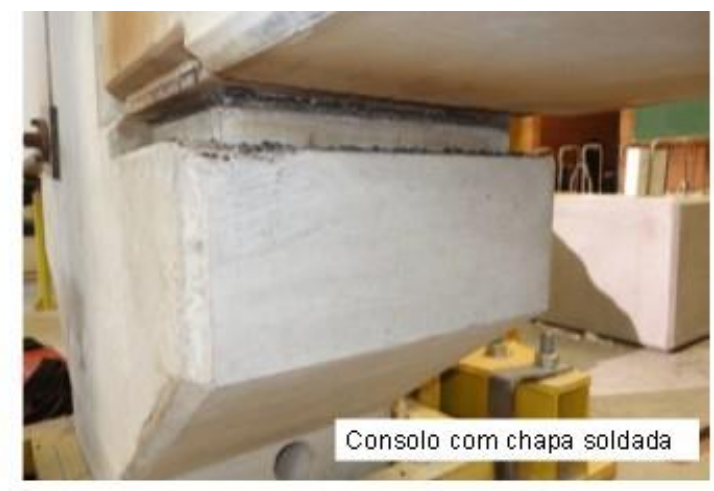

DIMENSÕES DO FILETE DE SOLDA

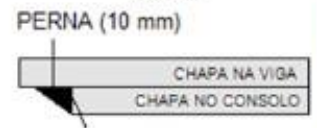

GARGANTA (7mm)

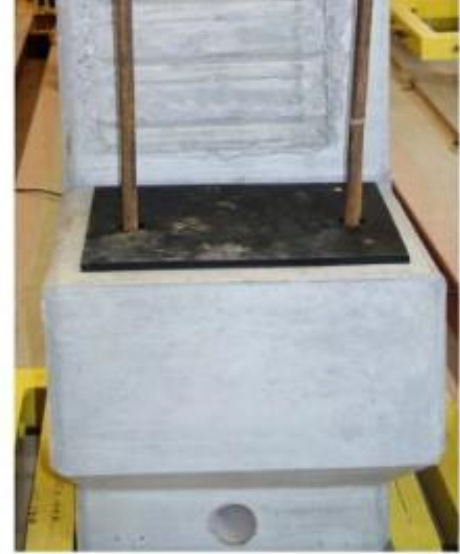

Consolo com chumbadore almofada de neoprene

Figura 10: Execução da solda para os modelos CS e CSE e consolo com chumbador e neoprene para os modelos NCE e NC.

\subsection{Metodologia para verificação da influência da rotação relativa viga-pilar na flecha total}

Foi utilizada uma metodologia para verificar a influência da rotação relativa viga-pilar na flecha total, ou seja, uma metodologia capaz de relacionar a flecha total da extremidade livre da viga e a rotação da ligação viga-pilar.

A flecha total na extremidade da viga em balanço é composta por duas parcelas, uma relativa a deformação da viga $\left(a_{1}\right)$ e, portanto, está relacionada com sua rigidez, e a outra relativa ao giro ocorrido na ligação $\left(a_{2}\right)$ e, portanto, depende da rotação efetiva entre a viga e o pilar. A parcela $\left(a_{1}\right)$ pode ser determinada a partir da equação diferencial de segunda ordem que governa a linha elástica da viga (Figura 11), onde $I_{e q}=0,5 I$, de acordo com a NBR 9062 [2]. A parcela $\left(a_{2}\right)$ pode ser determinada a partir da leitura em radiano do clinômetro posicionado na viga, subtraída da do pilar (Figura 11). Da mesma forma, a rotação viga-pilar pode ser obtida em função da flecha total na extremidade livre (Figura 11).

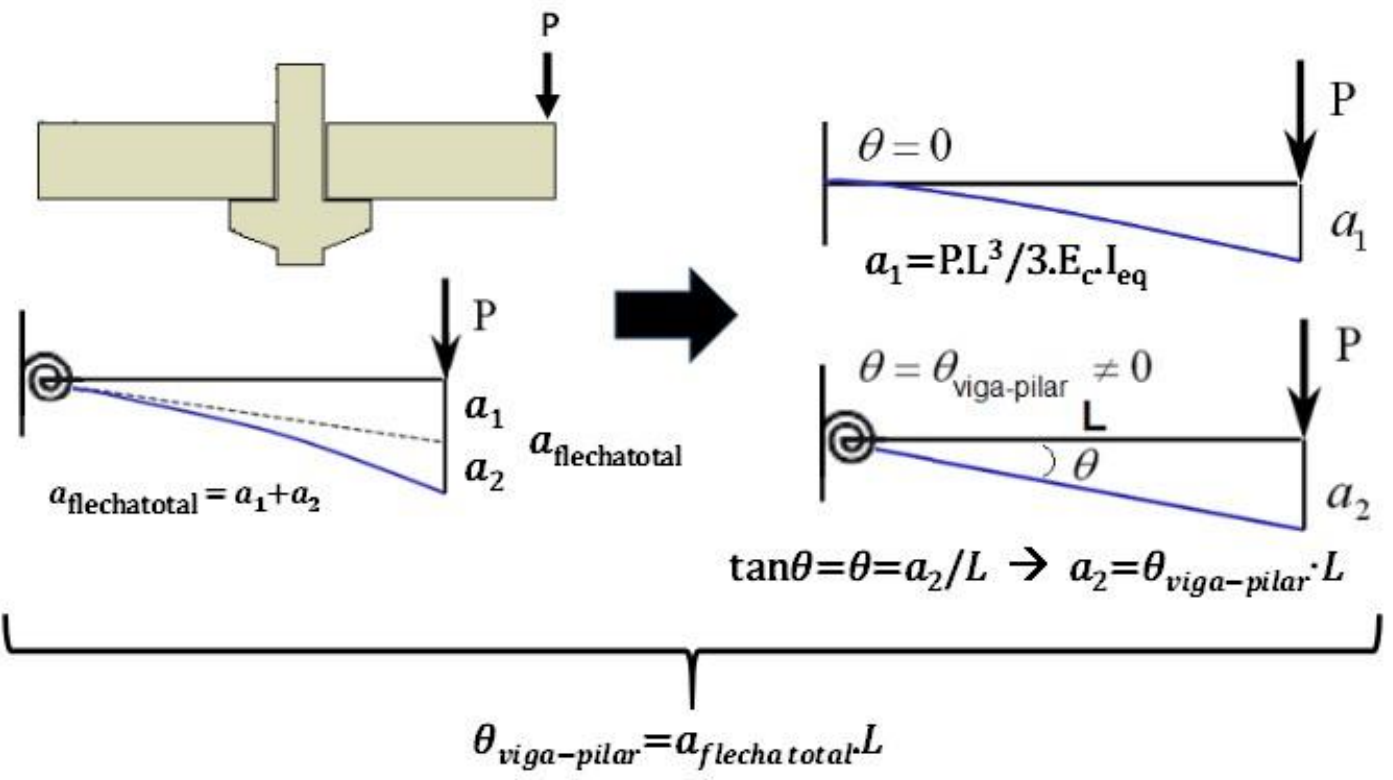

Figura 11: Metodologia que relaciona a rotação relativa viga-pilar e a flecha total na extremidade da viga. 


\section{RESULTADOS E DISCUSSÕES}

Ao se analisar os dados experimentais em HADADE [4], comparando os dados relativos às curvas de força aplicada nos atuadores nas extremidades livres versus deslocamento vertical com as curvas de força aplicada versus deformação específica (por meio de strain-gages) nas barras negativas, foi possível observar que as curvas de deslocamento vertical apresentaram um abatimento para uma força aplicada inferior à força aplicada onde ocorreu o abatimento no caso da curva de deformação específica, evidenciando que o abatimento nas curvas força-deslocamento ocorreu anterior ao escoamento da armadura negativa. De forma análoga, ficou evidenciado que o abatimento na curva momento-rotação acontece antes do início do escoamento da armadura. Portanto, a rigidez secante da relação momento-rotação está mais associada com mecanismos de abertura da interface viga-pilar, o qual pode ser intensificado na ocorrência de arrancamento parcial de graute de dentro da bainha de preenchimento, somando-se os efeitos de escorregamentos aço-concreto nas posições fissuradas na região da ligação nas proximidades da interface viga-pilar (na região da ligação na extremidade da viga).

Na Figura 12 estão apresentadas a curvas momento-rotação para os 6 protótipos ensaiados, enquanto na Figura 13 estão apresentadas as curvas momento-rotação normalizadas com base na curva momentorotação da ligação com almofada de elastômero (NCE).

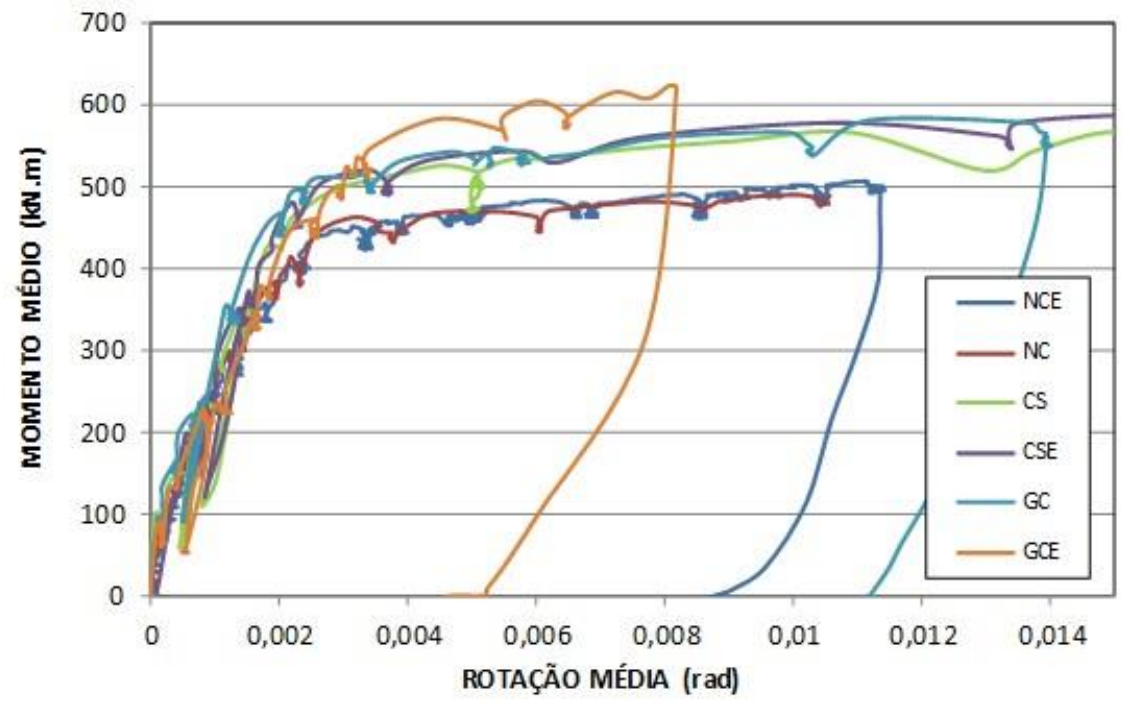

Figura 12: Comparação de gráficos Momento versus Rotação média

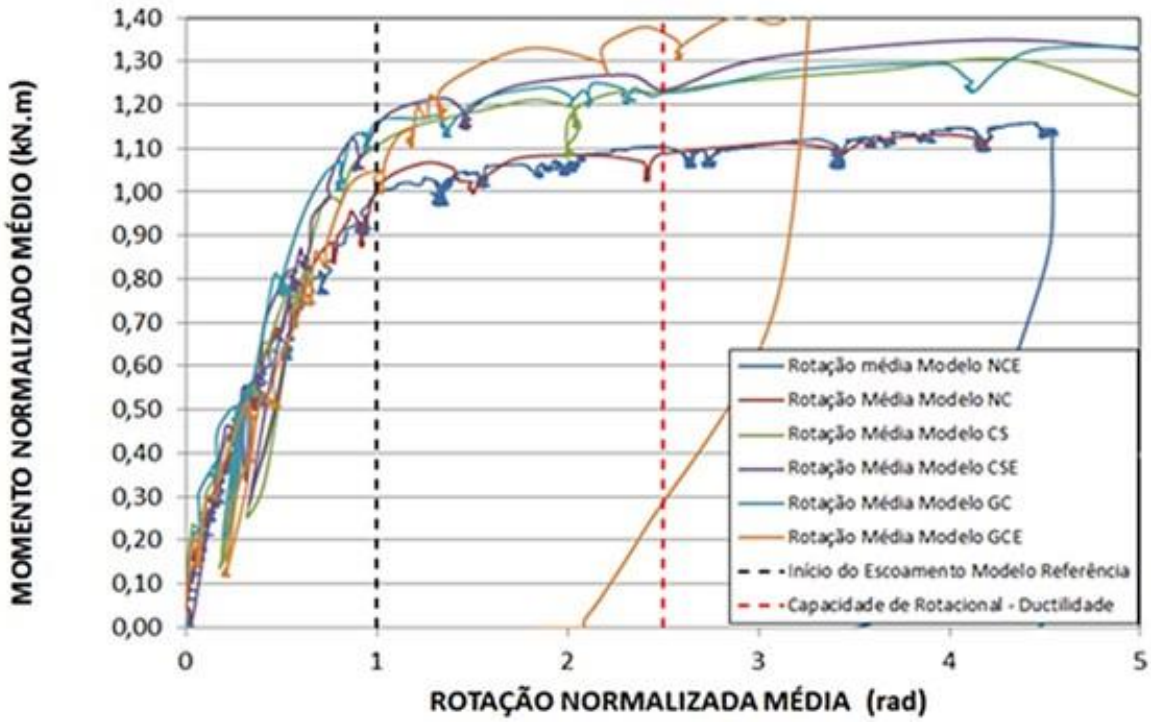

Figura 13: Comparação de gráficos Momento versus Rotação Normalizada média 
Com base nos resultados experimentais obtidos, foram feitas as seguintes observações:

a. Todas os protótipos de ligações apresentaram rigidez secante da relação momento-rotação da mesma ordem de grandeza. Enquanto a rigidez secante média para as ligações com chapas soldadas (CS e CSE) foi da ordem de $R_{\text {sec,exp }}=177.000 \mathrm{kN} . \mathrm{m} / \mathrm{rad}$, a qual foi apenas $11 \%$ superior à rigidez secante média das ligações com almofadas de elastômero (NC e NCE) de $R_{\text {sec,exp }}=160.000 \mathrm{kN} . \mathrm{m} / \mathrm{rad}$. Por outro lado, no caso da tipologia de ligação com juntas grauteadas, o protótipo $\mathrm{GC}$ apresentou rigidez similar à dos protótipos com almofadas, enquanto o protótipo GCE apresentou rigidez superior aos protótipos com chapas soldadas. Desta forma, pode-se deduzir que o detalhamento empregado para as ligações positivas apresentou pouca importância para a rigidez secante negativa da ligação.

b. Com base nas curvas momento-rotação na Figura 12, todas as ligações apresentaram capacidade total quanto à resistência à flexão, onde os momentos últimos $M_{u}$ superaram entre $18 \%$ a $28 \%$ os valores dos momentos no início do escoamento $M_{y, \text { exp }}$. Observando-se as curvas momento-rotação normalizadas na Figura 13, observa-se que as resistências nos modelos com chapas soldadas (CS e CSE) e os modelos com juntas horizontais grauteadas (GC e GCE) foram cerca de 10 a $20 \%$ superiores às resistências obtidas para os modelos com almofadas de elastômero (NC e NCE). Embora a posição da armadura negativa tenha sido igual em todos os modelos, para os casos das ligações com chapas soldadas e das ligações com juntas grauteadas (onde ocorreu um efeito de pino dos 2 chumbadores verticais com $20 \mathrm{~mm}$ de diâmetro na junta $10 \mathrm{~mm}$ ), as ligações positivas permitiram que a resultante de compressão na parte inferior da viga ficasse próxima à junta horizontal entre a viga e o consolo, aumentando assim o braço de alavanca $(z)$ que influi no momento fletor resistente na seção da ligação negativa. De fato, considera-se que para estas ligações (GC, GCE, CS e CSE) o braço de alavanca $(z)$ tenha ficado bem próximo da altura útil (d).

c. Considerando as curvas momento-rotação normalizadas na Figura 13, observou-se que embora ocorresse uma variação dos momentos fletores no nível do abatimento das curvas momento-rotação, quando foi analisada a leitura de rotação unitária pôde-se observar que todas as ligações apresentaram abatimento praticamente no ponto da rotação unitária, a qual foi obtida a partir da curva momento-rotação referente ao modelo NCE. Portanto, pode-se concluir que a variação nos valores para a rigidez secante se deu pela variação nos momentos fletores no início do abatimento das curvas momento-rotação, enquanto as rotações relativas viga-pilar associadas ao abatimento das curvas momento-rotação se mantiveram praticamente iguais para todos os modelos.

d. Em todos os modelos ensaiados as rotações últimas ultrapassaram duas vezes e meia o valor das rotações no início do escoamento, atendendo assim o critério de ductilidade segundo FIB [6].

Conforme pode ser observado na Figura 14, o padrão de fissuração, independentemente da ligação positiva, foi semelhante para todos os modelos ensaiados, com concentração de fissuras de flexão na região próxima à interface viga-pilar. Em função das dimensões da seção transversal das vigas, da tensão característica de tração do concreto, tensão de escoamento das barras de aço utilizadas e reduzida taxa da armadura transversal, não houve fissuras diagonais de cisalhamento, nem formação de rótula plástica. Verificou-se ainda que no estado limite de serviço a abertura das fissuras foi maior que as previstas pela ABNT NBR6118 [5], o que concorreu para o deslizamento aço-concreto. O mecanismo de deformação na ruptura está associado ao deslizamento aço-concreto na região fissurada, alongamento excessivo da armadura e arrancamento parcial do graute da bainha.

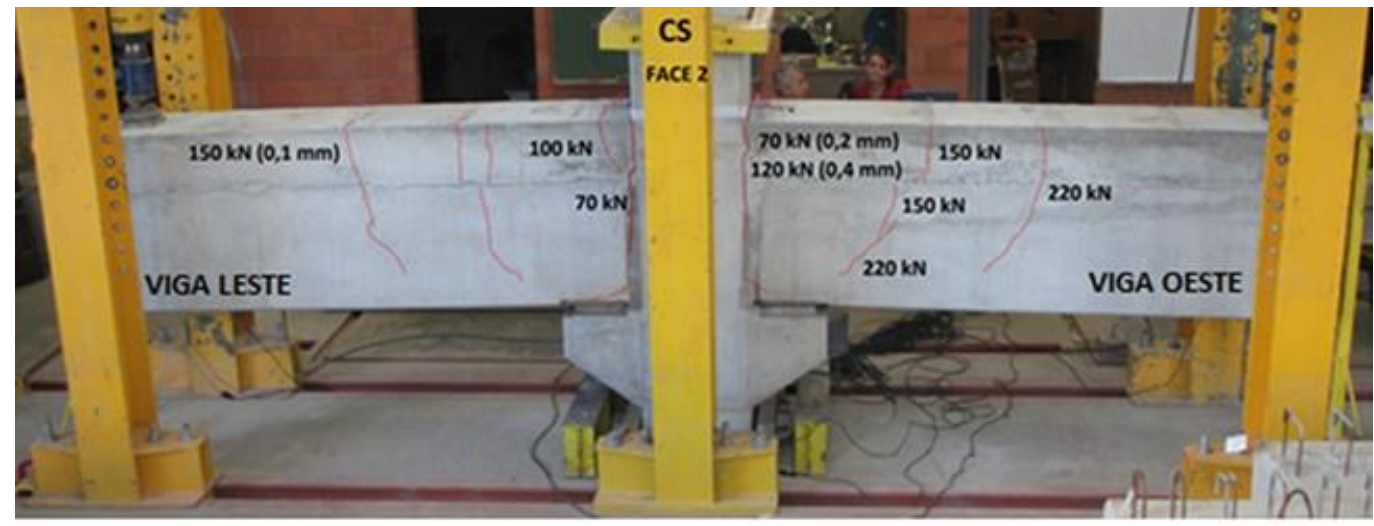

Figura 14: Configuração de fissuração dos modelos ensaiados. 
A Figura 15 apresenta gráfico da força no atuador versus o deslocamento vertical total obtido na posição das cargas aplicadas nas extremidades livres das vigas para o primeiro modelo com elastômero (NCE), o qual foi utilizado como referência para as curvas normalizadas momento-rotação (ver Figura 13). Conforme se observa na Figura 15, o deslocamento experimental foi muito superior que a flecha teórica $a_{l}=$ $\left[F L^{3} / 3\left(E_{c} I\right)_{s e c}\right.$, calculada com base na rigidez secante $\left(E_{c} I\right)_{s e c}=0,5 E_{c} I$ da viga pré-moldada de seção composta (com concretagem no local sobre a viga pré-moldada), apresentando forte evidencia que o deslocamento vertical na extremidade livre da viga em balanço não depende apenas da deformação não-linear das vigas de concreto armado, mas que de fato existe uma parcela bastante significante deste deslocamento que é devida ao giro de corpo rígido da viga decorrente da rotação relativa viga-pilar sobre o apoio no consolo. Confirmando esta hipótese, quando o deslocamento experimental é comparado com a flecha teórica total $a_{\text {total }}=a_{1}$ $+\theta_{\text {exp }} L$, onde a flecha teórica $a_{1}$ é adicionada a uma parcela de flecha decorrente do efeito do giro de corpo rígido com base na rotação experimental $\left(a_{2}=\theta_{\text {exp }} L\right.$, ), então se observa uma boa aproximação com a curva para o deslocamento total experimental. Portanto, ficou demonstrado que a rotação na ligação viga-pilar em decorrência do comportamento semirrígido provoca um aumento dos deslocamentos nas vigas pré-moldadas.

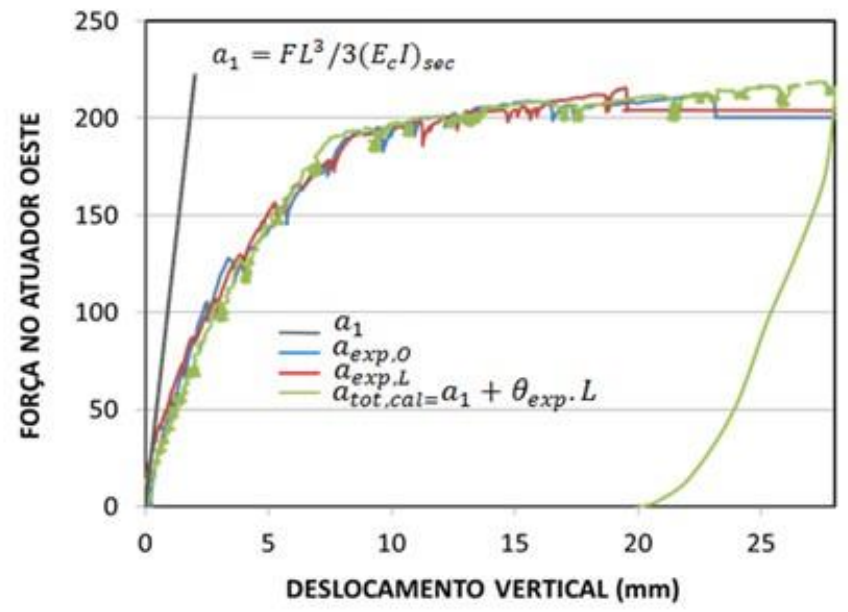

$$
\begin{aligned}
& a_{\text {tot }}=a_{1}+a_{2} \\
& a_{1}=F L^{3} / 3\left(E_{c} I\right)_{s e c} \\
& a_{2}=\theta L
\end{aligned}
$$

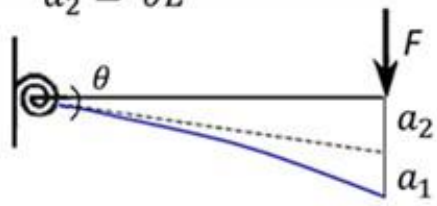

Figura 15: Comparação entre o deslocamento vertical experimental com flecha teórica calculada a partir da flecha teórica da viga pré-moldada com base na rigidez secante somada ao movimento de corpo rígido com base na rotação da ligação.

A Tabela 1 apresenta o valor da rigidez secante experimental $\left(R_{\text {sec,exp }}\right)$ para cada modelo e, considerando uma rigidez secante para a viga pré-moldada $\left(E_{c} I\right)_{s e c}=0,5 E_{c} I$ e adotando um comprimento virtual $L=12 h=10 \mathrm{~m}$, apresenta o fator de restrição à rotação $\left(\alpha_{R}\right)$ e o coeficiente de engastamento parcial da ligação $\left(\gamma_{E P}\right)$ para todos os modelos ensaiados. Conforme pode ser observado, o fator de restrição variou entre $0,54 \leq \alpha_{R} \leq 0,59$ e o coeficiente de engastamento parcial variou entre $0,64 \leq \gamma_{E P} \leq 0,68$, com um engasta-

\begin{tabular}{|c|c|c|c|c|c|c|c|c|}
\hline MODELO & $M_{y, \exp }$ & $\theta_{y, \exp }$ & $L_{e q}$ & $\begin{array}{l}F_{y} \\
=\frac{M_{y, e x p}}{L_{e q}}\end{array}$ & $\begin{array}{l}R_{\text {sec,exp }} \\
=\frac{M_{y, \exp }}{\theta_{y, \exp }}\end{array}$ & $\alpha_{R}=\frac{1}{1+\frac{3.0,5 I E_{c}}{R_{\text {sec. }} L_{\text {ef }}}}$ & $\gamma_{E P}=\frac{M_{S R}}{M_{E}}=\frac{3 \alpha_{R}}{2+\alpha_{R}}$ & $\begin{array}{c}\text { PARÂMETROS } \\
\text { CONSTANTES } \\
\text { A TODOS }\end{array}$ \\
\hline & (kN.m) & (rad) & (m) & (kN) & $(\mathrm{kN} \cdot \mathrm{m}) / \mathrm{rad}$ & $\alpha_{R}$ & $\gamma_{E P}(\%)$ & OS MODELOS \\
\hline T1-NCE & 397 & 0,0025 & 2,10 & 189 & 158.297 & 0,54 & 0,64 & $I\left(\mathrm{~mm}^{4}\right)$ \\
\hline T1-NC & 400 & 0,0025 & 2,15 & 186 & 160.708 & 0,54 & 0,64 & $2,56 \mathrm{E}+10$ \\
\hline T1-GCE & 450 & 0,0028 & 2,11 & 213 & 161.466 & 0,55 & 0,64 & Ec (GPa) \\
\hline T1-GC & 452 & 0,0024 & 2,14 & 211 & 191.911 & 0,59 & 0,68 & 35,00 \\
\hline T2-CSE & 470 & 0,0026 & 2,18 & 215 & 177.586 & 0,57 & 0,66 & $L_{e f}(m m)$ \\
\hline T2-CS & 439 & 0,0025 & 2,16 & 203 & 176.861 & 0,57 & 0,66 & $10.000,00$ \\
\hline
\end{tabular}
mento parcial médio em torno de $65 \%$.

Tabela 1: Comparação de dados experimentais e teóricos para todos os modelos 


\section{CONCLUSÕES}

Com base nos resultados experimentais, observou-se que todas as ligações ensaiadas apresentaram rigidez secante com mesma ordem de grandeza, fornecendo uma forte evidência que ela foi pouco influenciada pelo tipo de detalhamento utilizado na ligação positiva, onde a rigidez média obtida nos modelos com chapas soldadas foi cerca de $11 \%$ superior à rigidez média obtida nos modelos com elastômero. Portanto, o uso de ligações positivas com chapas soldadas é indicado somente para situações onde houver reversão de momento devido às ações horizontais de vento, mas não como solução para aumentar da rigidez secante negativa. Por outro lado, pode-se concluir que a rigidez secante negativa é fortemente associada com o mecanismo de deformação por alongamento da armadura negativa, com ocorrência do escorregamento aço-concreto nas posições fissuradas da região da ligação anterior ao escoamento da armadura, mas com intensificação deste mecanismo com a abertura na interface viga-pilar a partir do arrancamento parcial de graute de preenchimento na bainha corrugada. Considerando uma viga de concreto armado com rigidez secante de $\left(E_{c} I\right)_{s e c}=0,5 E_{c} I \mathrm{e}$ comprimento virtual $L=12 h(h=$ altura da viga), obteve-se um coeficiente médio de engastamento parcial em torno de $65 \%$.

\section{AGRADECIMENTOS}

Os autores agradecem todas as instituições que tornaram esta pesquisa possível. À FAPESP pelos equipamentos utilizados no laboratório do NETPRE. À UFSCar pela infraestrutura e pessoal técnico para os ensaios. À ABCIC pelo apoio institucional com a doação do prédio do laboratório NETPRE. À T\&A Pré-fabricados pela doação dos modelos e disponibilização de pessoal técnico para colaboração na pesquisa.

\section{BIBLIOGRAFIA}

[1] ELLIOT, K. S., DAVIES, G., FERREIRA, M.A., et al., (2003). "Can Precast Concrete Structures be Designed as semi-rigid frames: Part 1 - The experimental evidence". The Structural Engineer. International Journal of the Institution of Structural Engineers. v.81, n.16 (Aug.19). London, United Kingdom.

[2] ASSOCIAÇÃO BRASILEIRA DE NORMAS TÉCNICAS (ABNT), NBR 9062 - Projeto e execução de estruturas de concreto pré-moldado, Rio de Janeiro, 2006.

[3] FERREIRA, M. A. Deformabilidade de ligações viga-pilar de concreto pré-moldado. São Carlos, Tese de D.Sc., Escola de Engenharia de Estruturas (EESC-USP), 1999.

[4] HADADE, M. A. S. Comportamento de Ligações Viga-Pilar Típicas com Continuidade de Armadura Negativa. São Carlos, Tese de D.Sc., Universidade Federal de São Carlos (UFSCar), 2016.

[5] ASSOCIAÇÃO BRASILEIRA DE NORMAS TÉCNICAS (ABNT), NBR 6118 - Projeto de estruturas de concreto - procedimento, Rio de Janeiro, 2004.

[6] FIB GUIDE TO GOOD PRACTICE. Structural Connections for Precast Concrete Buildings. Bulletin 43 - 2003. Commission C6: Prefabrication. Task Group 6.2: Connections, 2003. 